\title{
Tava Guarani: de lugar simbólico a Patrimônio Cultural do MERCOSUL
}

\author{
Tava Guarani: from simbolic place to Cultural Heritage of MERCOSUR
}

\author{
Helena Amanda Faller Tagarro \\ Geógrafa e Mestranda em Preservação do Patrimônio Cultural - IPHAN/DF, Brasil \\ helenafaller.89@gmail.com
}

\begin{abstract}
Resumo
O presente artigo traz uma breve discussão acerca do reconhecimento da Tava Guarani como Patrimônio Cultural do MERCOSUL. A Tava está localizada no município de São Miguel das Missões/RS e faz parte do conjunto do Patrimônio Missioneiro. O Patrimônio Missioneiro, por sua vez, é composto por quatro sítios históricos tombados pelo Instituto do Patrimônio Histórico e Artístico Nacional, sendo os quatro também reconhecidos pelo MERCOSUL e um deles reconhecido como Patrimônio Mundial pela UNESCO. Além disso, há também o registro da Tava como Patrimônio Imaterial Brasileiro pelo IPHAN e, mais recentemente, seu reconhecimento como Patrimônio Cultural do MERCOSUL. Assim, a proposta deste estudo é de apresentar a importância da candidatura e, consequentemente, do reconhecimento da Tava para o MERCOSUL, considerando o interesse do bloco de fomentar a integração entre seus Estados-Partes em diferentes áreas, inclusive a cultura. Para isso, consta também um breve apontamento acerca do funcionamento do MERCOSUL Cultural, órgão interno responsável pelos reconhecimentos dos bens culturais. Esse artigo é fruto da pesquisa de mestrado que vem sendo desenvolvido, em que se busca compreender a participação do Brasil, enquanto Estado nacional, no âmbito dos reconhecimentos dos patrimônios em nível internacional.
\end{abstract}

Palavras-chave: Patrimônio, Reconhecimento, MERCOSUL.

\begin{abstract}
The article brings a discussion of the recognition of Tava Guarani as Cultural Heritage of MERCOSUR. Tava is located in the municipality of São Miguel das Missões/RS and is part of the set of Missionary Heritage. The Missionary Heritage, in turn, is composed of four registered historical sites by the National Historical and Artistic Heritage Institute (IPHAN), being all also recognised by MERCOSUR and one of them recognised as World Heritage by UNESCO. Besides, there is also the registration of Tava as Brazilian Intangible Heritage by IPHAN and, more recently, its recognition as a Cultural Heritage of MERCOSUR. Thus, the proposal of this study is to present the importance of the application and, consequently, the recognition of Tava for MERCOSUR, considering the interest of the block to promote the integration among its States Parties in different areas, including culture. In this regard, there is also a brief note about the functioning of MERCOSUR Cultural, an internal entity responsible for the recognition of cultural assets. This article is the result of the master's research that has been developed, which seeks to understand the participation of Brazil, as a national State, in the scope of recognising the heritages at the international level.
\end{abstract}

Keywords: Heritage, Recognition, MERCOSUR. 


\section{INTRODUÇÃO}

A Região das Missões, localizada no noroeste do Rio Grande do Sul, conta com um número significativo de bens reconhecidos como patrimônio cultural. Cada reconhecimento ocorreu em um período histórico diferente, atendendo as expectativas para cada época e situação. O primeiro bem a ser tombado pelo Instituto do Patrimônio Histórico e Artístico Nacional - IPHAN foi o Sítio Histórico de São Miguel Arcanjo, em 1938¹; uma época em que tal instituto acabara de ser criado, em $1937^{2}$, e vinha construindo sua imagem perante o Estado e a sociedade, de modo a consolidar suas políticas de patrimônio. Somente em 1970 outros três sítios históricos foram tombados pelo IPHAN, mas sob outra leitura do bem. Enquanto que o tombamento de 1938 levou em consideração a imponência do sítio, resultando na sua inscrição no Livro do Tombo de Belas Artes, os outros três foram inscritos no Livro do Tombo Histórico ${ }^{3}$. Os sítios em questão são: Sítio Histórico de São João Batista, São Nicolau e São Lourenço Mártir (Figura 01).

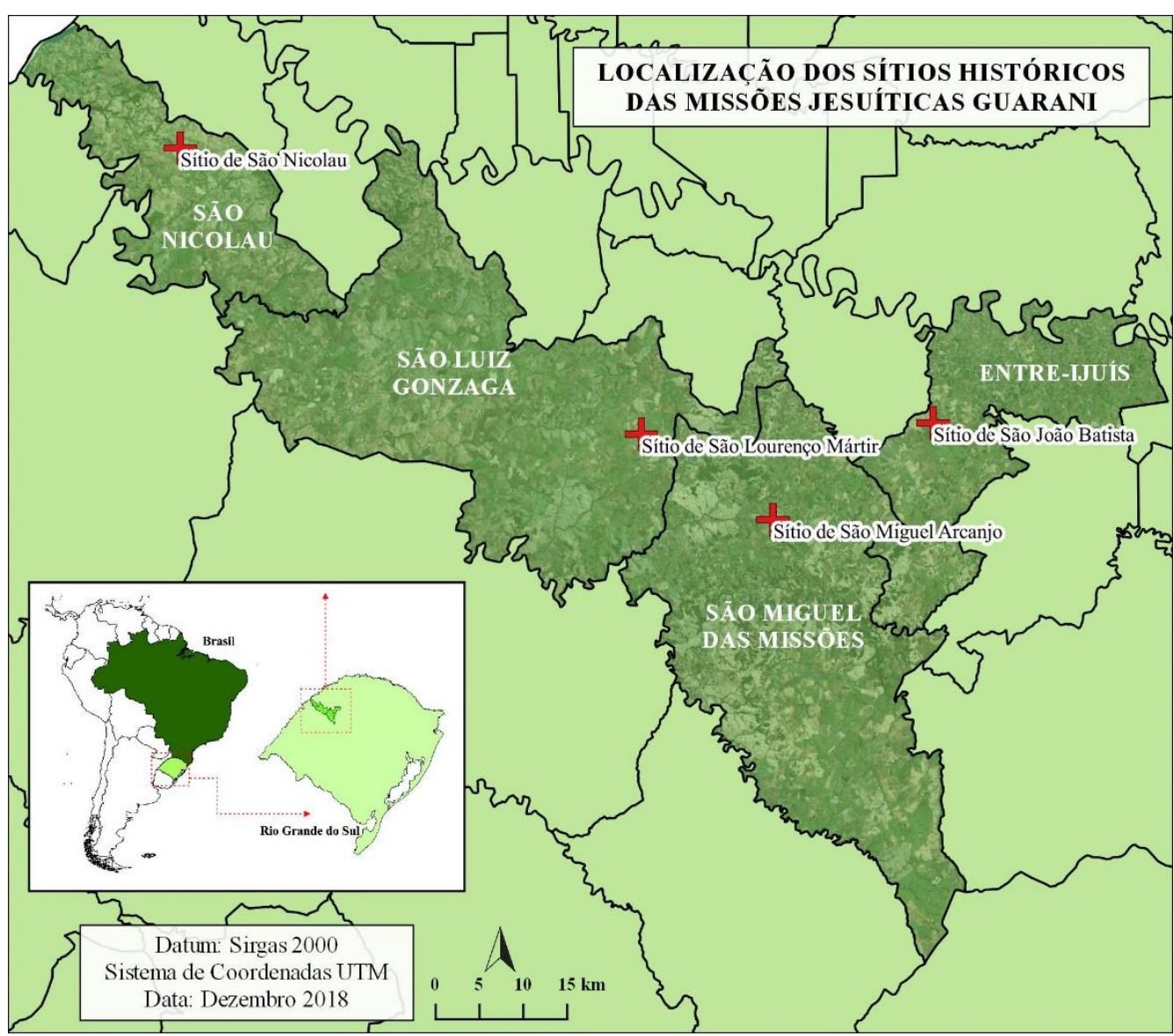

Figura 1 - Localização dos Sítios Históricos acautelados pelo IPHAN. Organização: Helena Faller.

Fonte: Geoserver/IPHAN .

\footnotetext{
${ }^{1}$ IPHAN. Livro do Tombo das Belas Artes - Volume 1. Inscrição n ${ }^{\circ}$ 63. Processo n ${ }^{\circ}$ 141-T-38.

${ }^{2}$ Criação mediante o Art. 46 da Lei no 378 de 13 de janeiro de 1937.

${ }^{3}$ IPHAN. Livro do Tombo Histórico - Volume 1. Inscrição no 423 a; no 424 a; no 426 a. Processo no 813-T-69.
} 
Em 1983, a UNESCO inscreveu o Sítio Histórico de São Miguel Arcanjo na Lista do Patrimônio Mundial junto com mais 4 sítios argentinos, Sítio de San Inacio de Mini, Loreto, Santa Ana e Santa Maria de la Mayor ${ }^{4}$. Essa inscrição corresponde a um bem seriado e transfronteiriço, uma vez que não se refere apenas a um bem, além de ultrapassar as fronteiras nacionais entre o Brasil e a Argentina. Esse é o ponto que começa a chamar atenção neste estudo: as relações entre os Estados em prol da patrimonialização. A década de 1980 foi o período de maior aproximação entre o Brasil e a Argentina, de tal modo que, em 1988, ambos os países assinaram um acordo bilateral em que foi instituído o Grupo Mercado Comum que, posteriormente, veio a se tornar o MERCOSUL (OLIVEIRA, 1997).

O MERCOSUL surgiu, em 1991, mediante a assinatura do Tratado de Assunção pelo Brasil, Argentina, Paraguai e Uruguai, e a proposta era de fomentar a integração política e econômica entre os Estados-Partes, possibilitando o comércio entre eles e o desenvolvimento dos mercados. Além disso, a preocupação posta pelo tratado não era de desenvolver a economia de maneira descontínua, mas propor medidas de crescimento igualitário e justo entre os Estados, evitando discrepâncias entre eles (BRASIL, 1991). No entanto, para além das questões econômicas, o MERCOSUL tinha como proposta promover uma real união entre os Estados através de sua política integracionista. Tal política apresentou boa repercussão, o que possibilitou no avanço da discussão sobre outros assuntos, que não a economia. Assim, o leque de interesses do bloco se ampliou abrangendo outras categorias como a educação, a saúde e a cultura.

A respeito da cultura, interessa dizer que, em 1996, foi assinado o Protocolo de Integração Cultural durante a Reunião de Ministros da Cultura ocorrida na cidade de Fortaleza/CE. Esse protocolo foi assinado com o interesse de promover as expressões culturais e artísticas da região, utilizando-se acordos de cooperação e intercâmbios entre os Estados-Partes (LESSA, 2010). Tendo como foco a integração cultural, em 2012, o MERCOSUL Cultural - entidade interna do bloco lançou a Decisão no 55 que cria a categoria de Patrimônio Cultural do MERCOSUL (PCM) e determina alguns critérios a serem analisados para o seu reconhecimento.

Com a instituição do Patrimônio Cultural do MERCOSUL em 2012, foi dado início aos processos de reconhecimento dos bens culturais presentes na região. Retorno, então, para a lista dos diferentes tipos de reconhecimento do Patrimônio Missioneiro. Foi mencionado os quatro sítios acautelados pelo IPHAN, ou seja, na esfera federal, e mais o reconhecimento por parte da UNESCO, como Patrimônio Mundial. Agora, porém, tem-se o reconhecimento dos mesmos sítios como Patrimônio Cultural do MERCOSUL, sob o título de "Missões Jesuíticas Guarani, Moxos e

\footnotetext{
${ }^{4}$ UNESCO. World Heritage List. Jesuit Missions of the Guaranis: San Ignacio Mini, Santa Ana, Nuestra Señora de Loreto and Santa Maria Mayor (Argentina), Ruins of Sao Miguel das Missoes (Brazil). Disponível em: http://whc.unesco.org/en/list/275. Acesso em: março/2019.
} 
Chiquitos" ${ }^{\text {. }}$. Assim como é pela UNESCO, tal reconhecimento se refere a um bem seriado e transfronteiriço, contudo, de maior alcance, abrangendo a Argentina, Bolívia, Brasil, Paraguai e Uruguai.

Embora esses dois reconhecimentos internacionais chamem atenção por sua característica transfronteiriça, o reconhecimento da Tava também merece destaque por sua relação com o território. Em 2014 ocorreu o registro da Tava: Lugar de Referência para o Povo Guarani, inscrita no Livro de Lugares, fruto do Inventário Nacional de Referências Culturais (INRC) sobre os Mbyá Guarani que trouxe a perspectiva de um novo olhar sobre o território missioneiro, possibilitando uma abordagem do ponto de vista indígena em relação ao Patrimônio das Missões, no qual eles puderam apresentar suas narrativas sobre a história (IPHAN, 2014).

Tendo em vista a identificação de que é importante incluir os guarani nos debates sobre o patrimônio cultural, sobretudo o que está presente na Região das Missões, pensou-se em uma nova possibilidade de reconhecimento para a Tava, desta vez no âmbito do MERCOSUL. No entanto, essa candidatura teve como objetivo ampliar a discussão sobre a cultura indígena na América do Sul, principalmente dos guarani, possibilitando a troca de conhecimentos acerca do assunto. Assim, foi postulada a candidatura da Tava durante a XVI Reunião da Comissão do Patrimônio Cultural ${ }^{6}$ realizada no Paraguai, no primeiro semestre de 2018 e, durante a XVII Reunião da $\mathrm{CPC}^{7}$ ocorrida no Uruguai, em outubro de 2018, a Tava: Lugar de Referência para o povo Guarani foi reconhecida como Patrimônio Cultural do MERCOSUL (Figura 2).

A proposta deste artigo, portanto, é de trazer o processo de reconhecimento da Tava como Patrimônio Cultural do MERCOSUL, identificando nesse reconhecimento o discurso de integração cultural proposto pelo bloco, assim como apontar a importância do bem para o povo guarani. No presente trabalho também consta uma breve apresentação das reduções jesuíticas para situar historicamente o surgimento desta tava que veio a ser patrimonializada posteriormente. Ademais, é interesse que se apresente o que são as tava e sua relação com o povo guarani e seu território tradicional, para enfim, compreender o processo integracionista mercosulenho.

\footnotetext{
5 IPHAN. Missões Jesuíticas Guaranis, Moxos e Chiquitos - Brasil e Argentina. Disponível em: http://portal.iphan.gov.br/pagina/detalhes/1127/. Acesso em: março/2019.

${ }^{6}$ MERCOSUL. MERCOSUL Cultural. Ata da XVI Reunião da Comissão do Patrimônio Cultural realizada nos dias 05 e 06 de abril de 2018, p. 1-9.

${ }^{7}$ MERCOSUL. MERCOSUL Cultural. Ata da XVII Reunião da Comissão do Patrimônio Cultural realizada nos dias 30 e 31 de outubro de 2018, p. 1-13.
} 


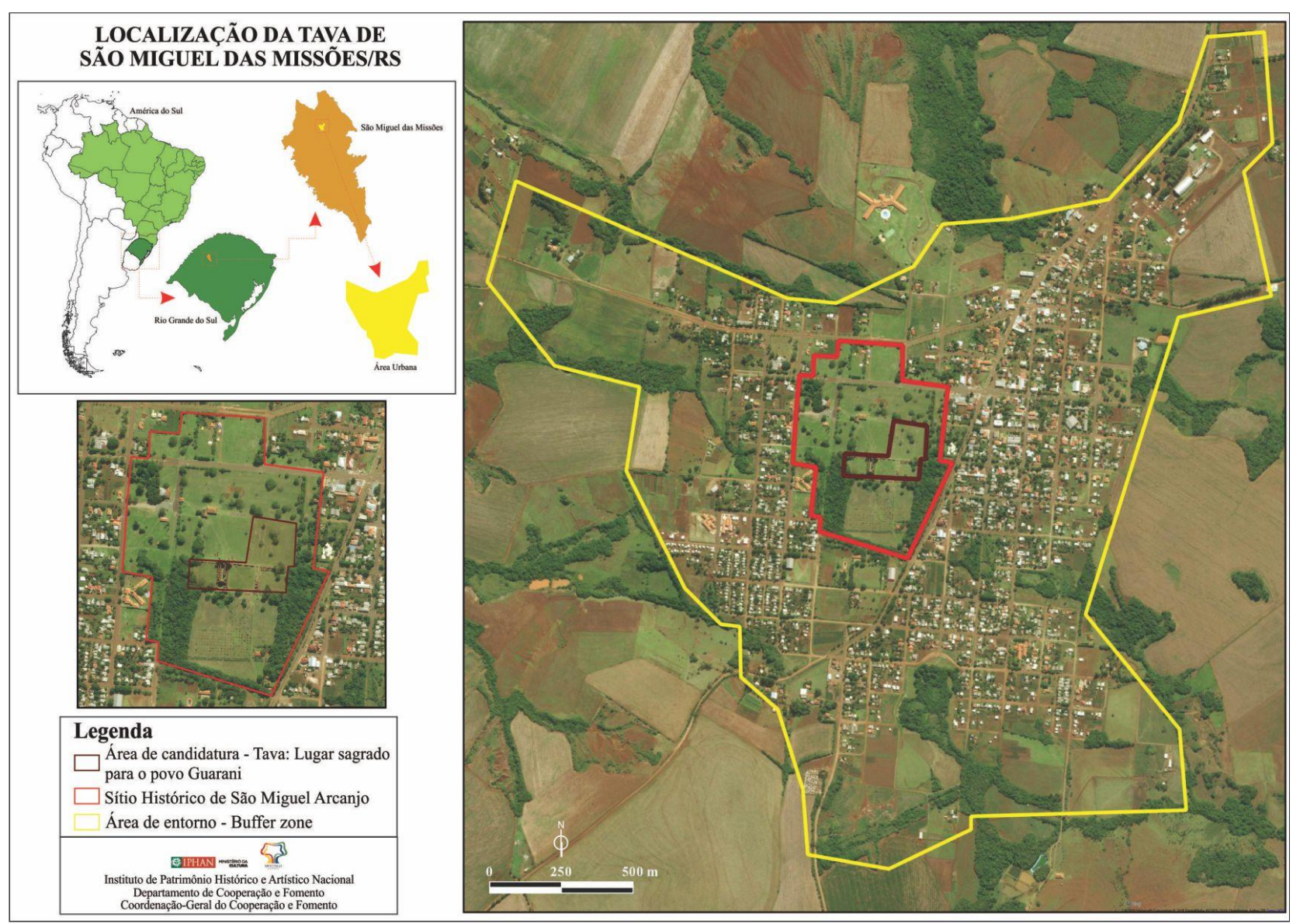

Figura 2 - Localização da Tava: Lugar de Referência para o povo Guarani - Patrimônio Imaterial Brasileiro e Patrimônio Cultural do MERCOSUL.

Fonte: Dossiê de Candidatura da Tava a Patrimônio Cultural do MERCOSUL, IPHAN 2018.

\section{AS REDUÇÕES JESUÍTICAS GUARANI}

Os séculos XVI e XVII foram marcados por grandes transformações espaciais no continente recém-descoberto pelos portugueses e espanhóis, a América. O continente, que já era habitado por diferentes povos que possuíam seus próprios modos de vida, foi ocupado pelas Coroas Ibéricas que desconsideraram as vivências existentes e impuseram no novo território sua própria realidade. Inclusive deve ser lembrado a divisão territorial mediante o Tratado de Tordesilhas, assinado em 1494 entre as duas coroas, que determinou que a 370 léguas a oeste das ilhas de Açores seria o limite entre as terras portuguesas e espanholas. As terras a direita dessa linha pertenceriam à Espanha e a esquerda, pertenceriam à Portugal (MAEDER, 2009). As ocupações realizadas por ambos os países no continente sul-americano obedeceram aos limites determinados pelo tratado, e cada qual se apropriou segundo seus modelos de organização espacial.

O território missioneiro que hoje faz parte da atual composição espacial do estado do Rio Grande do Sul, à época do início da colonização, pertencia à Coroa Hispânica, o que justifica a existência das reduções jesuíticas ligadas aos espanhóis naquela região. Os jesuítas, por sua vez, estiveram presentes em vários momentos históricos do Brasil, sendo responsáveis pela construção 
de inúmeras igrejas, colégios, portos e vilas. Uma das ações mais efetivas desses religiosos foi o estabelecimento das reduções, no início do século XVII, que segundo Baptista (2010), eram parte importante do projeto missional, que tinha como um de seus objetivos a evangelização dos indígenas de modo que eles fossem "reduzidos" ao padrão de vida europeu. De acordo com Custódio (2011) e Stello (2013), a proposta missional não se restringia apenas à evangelização, mas que possuía características de busca pela estabilização do poder político, social e econômico sobre a colônia e seus habitantes. Inicialmente, as missões foram implementadas em diferentes localidades divididas em cinco regiões missioneiras, das quais são Itatin, Guayra, Iguazu Acarai, Uruguay e Tape, todas essas regiões mantinham-se distanciadas entre si (MAEDER, 2009).

As reduções jesuíticas eram caracterizadas por manterem uma administração comunitária, havendo espaços de usos comuns como capelas e depósitos. Além disso, possuía uma infraestrutura que atendia não só os centros urbanos, como as áreas de cultivos e de criação de gado (STELLO, 2013). Apresentava um caráter hierárquico, o qual os padres eram os representantes máximo do poder; entretanto, ainda dentro daquela estrutura, os nativos, isto é, os indígenas, também possuíam certa autonomia diante do sistema missioneiro. Essa autonomia pode ser entendida através da composição espacial presente nas reduções, pois a proposta de organização seguia uma lógica familiar, muito comum aos modelos de organização dos próprios Guarani, com a existência de cacicados que hoje são conhecidos, pela etnologia, como famílias extensas (BAPTISTA, 2010). Esses espaços familiares, segundo Stello (2013), tinham áreas de usos coletivos, e as casas eram construídas ao seu redor; em relação à estrutura social, os cuidados domésticos e a agricultura eram de responsabilidade das mulheres, enquanto a responsabilidade com a caça e a pesca eram dos homens.

A organização missioneira foi se aperfeiçoando com o passar do tempo, sobrevivendo, inclusive, à invasão dos bandeirantes vindos de São Paulo, ainda no século XVII, até chegar ao formato de trinta povos das missões que deu origem à Província Jesuítica do Paraguai entre os séculos XVI e XVII. Com a atual delimitação política-territorial da América Latina, esses trinta povos encontram-se distribuídos entre quinze na Argentina, oito no Paraguai e sete no Brasil.

Os sete povos das missões situados em território brasileiro estão localizados no noroeste do estado do Rio Grande do Sul, e hoje compreende a "Região das Missões" com 26 municípios que integram a Associação dos Municípios das Missões ${ }^{8}$. Quatro desses sete povos, isto é, das antigas reduções, apresentam remanescentes da presença jesuítica e guarani e, por isso, são acautelados pelo IPHAN através da legislação federal de tombamento. Os remanescentes dos povos ou reduções hoje são denominados Sítios Históricos. Porém, antes mesmo do primeiro bem ser tombado, em

${ }^{8}$ AMM - Região Missioneira. Disponível em: http://ammissoes.com.br/historia. 
1938, a região já recebia atenção governamental das esferas municipais e estadual em prol da proteção dos elementos históricos referentes à presença das reduções jesuíticas-guarani no território (STELLO, 2013).

Atualmente, a Região Missioneira é referências na execução de ações e políticas voltadas para a preservação do patrimônio cultural. Assim, não ficou restrito apenas aos patrimônios edificados, como é o caso dos sítios históricos tombados, mas buscou ampliar o debate acerca da importância de preservar a cultura e a identidade local, atraindo novos reconhecimentos, principalmente no âmbito internacional. Os reconhecimentos para além dos tombamentos têm o cerne a localização do patrimônio missioneiro em uma área de fronteira. Deste modo, em 1983, o primeiro reconhecimento internacional por parte da UNESCO trouxe a perspectiva de um bem transfronteiriço, considerando as Missões Jesuíticas um todo indivisível. Assim também aconteceu com o reconhecimento pelo MERCOSUL em 2015, que além das missões realizadas pelos jesuítas sobre os guarani, incluíram as dos moxos e chiquitos, outros grupos indígenas existentes na América do Sul. O que se pretende dizer é que, a Região das Missões é uma região de fronteira e os reconhecimentos de seu patrimônio podem surtir algum efeito sobre essa situação.

Mesmo a Tava, reconhecida nacionalmente como Patrimônio Imaterial Brasileiro, em 2014, não ignora a importância das fronteiras nacionais. Na verdade, como pode ser observada no seu dossiê de registro (IPHAN, 2014), a proposta de seu reconhecimento veio com base na existência do chamado "território tradicional guarani" que ocupa parte do Brasil, Argentina e Paraguai (Figura 3). A Tava, como um lugar simbólico, torna-se também um lugar referencial para o estabelecimentos das aldeias, pois para os guarani, ela corresponde a um lugar sagrado, uma representação de uma "casa de pedra", marcada pela presença dos imortais Guarani, que eles chamam de primeiros Mbyá, que alcançaram a "Terra sem Mal”. Assim, sempre que uma Tava é identificada é necessário que se construa uma opy (casa de oração) próximo para se erguer uma nova aldeia e dar continuidade ao modo de vida Guarani. A Tava só pode ser vista pelos Karaí, líder espiritual dos Mbyá, e geralmente são associadas à elementos da natureza, como formação rochosa e relevo. A Tava localizada em São Miguel das Missões/RS possui uma particularidade por ser visível tanto aos olhos dos outros Mbyá, quanto aos olhos dos Juruá (não-indígenas). E essa particularidade é explicada pelos guarani como ser o desejo de Nhanderu de fazer dela visível para que todos pudessem acreditar nas narrativas sagradas e, assim, viver de maneira consciente e respeitosa tanto entre si quanto com a natureza (IPHAN, 2014).

Considerando que o território tradicional guarani ultrapassa os limites territoriais nacionais e sendo a Tava uma representação desse mesmo território, o seu reconhecimento como Patrimônio Cultural do MERCOSUL também envolve debates acerca das fronteiras nacionais. Desta forma, é 
possível dizer que o patrimônio de fronteira nem sempre está associado à sua localização fronteiriça, como é o caso dos sítios tombados, mas podem estar relacionados aos processos identitários e de composição territorial e cultural, como é o caso da Tava para os guarani.

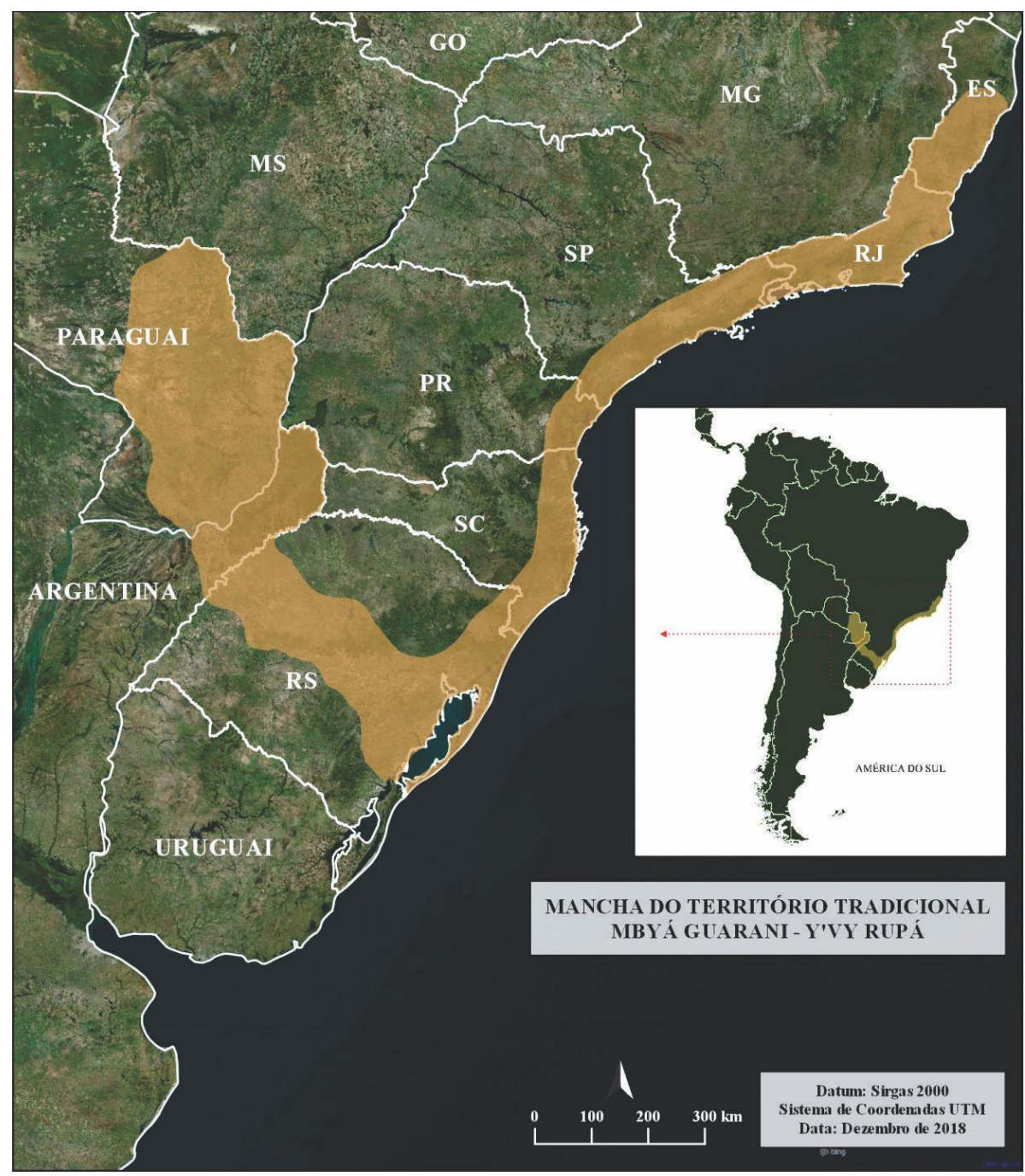

Figura 3 - Território Tradicional Guarani - povo Mbyá Guarani. Organização: Helena Faller. Fonte: Cartografia Digital Guarani - https://guarani.map.as/\#!/.

\section{O MERCOSUL E O RECONHECIMENTO DA TAVA COMO PATRIMÔNIO CULTURAL}

Os patrimônios reconhecidos pelo MERCOSUL seguem alguns critérios estabelecidos pela Decisão N ${ }^{o}$ 55/2012 do Conselho do Mercado Comum, que cria a categoria de Patrimônio Cultural do MERCOSUL (PCM). A criação desta categoria é fruto da instituição do MERCOSUL Cultural que, mediante a Decisão $\mathrm{N}^{\mathrm{o}} 15 / 2012$, passou a ser o nome utilizado para se referir à Reunião de Ministros da Cultura do MERCOSUL, existente desde 1995, sob a Decisão 02/1995 do Conselho do Mercado Comum, com o intuito de promover a integração dos Estados-Partes também na área de cultura. 
Desde 1995 o MERCOSUL vem atuando em outros assuntos para além da economia, em que através do Conselho do Mercado Comum, instituiu as reuniões de ministros ligados a esses assuntos, como a Agricultura (RMA), a Educação (RME), Indústrias (RMIND), a Justiça (RMJ), o Meio Ambiente (RMMA), a Saúde (RMS), o Trabalho (RMT) e a Cultura (RMC). E, embora essas discussões tenham iniciadas já em meados da década de 1990, somente em 2012 que o Patrimônio Cultural conquistou seu espaço dentro do bloco. O Art. $3^{\circ}$ do Regulamento para Reconhecimento do Patrimônio Cultural do MERCOSUL fala sobre a caracterização que,

\footnotetext{
Poderá ser reconhecido como Patrimônio Cultural do MERCOSUL (PCM) qualquer bem cultural, de natureza material e/ou imaterial, que:

a) Manifeste valores associados a processos históricos vinculados aos movimentos de autodeterminação ou expressão comum da região perante o mundo;

b) Expresse os esforços de união entre os países da região;

c) Esteja diretamente relacionado a referências culturais compartilhadas por mais de um país da região;

d) Constitua fator de promoção da integração dos países, com vistas a um destino comum.
}

Com base nesses critérios, é possível notar que a candidatura da Tava se aplica a todos eles, tendo em vista não apenas sua importância para o povo Mbyá Guarani, mas a integração que ela pode proporcionar aos três países que têm em comum a participação desse povo na construção de suas histórias, sendo eles o Brasil, a Argentina e o Paraguai. As Missões Jesuíticas Guarani estiveram presentes nesses três países e também no Uruguai, embora neste último não houve nenhuma redução edificada.

Se observar atentamente, todos os critérios do MERCOSUL buscam pela integração cultural, sendo necessário, portanto, que o bem em candidatura tenha algum tipo de relação com, ao menos, outro país da região. E o estabelecimento desses critérios é proveniente do Protocolo de Integração Cultural do MERCOSUL, assinado em 16 de dezembro de 1996, pelos Estados-Partes, que tem como objetivo a valorização e promoção das manifestações culturais dos países do MERCOSUL por meio de projetos e intercâmbios, buscando através da união cumprir com os objetivos (LESSA, 2010).

A integração é o fator preponderante para o desenvolvimento de qualquer área dentro do MERCOSUL, isso porque ela é componente base da assinatura do Tratado de Assunção, responsável por criar e instituir o MERCOSUL, em 1991 (BRASIL, 1991). Portanto, é fundamental que o patrimônio a ser reconhecido pelo MERCOSUL expresse, de alguma maneira, o processo integracionista proposto pelo bloco, seja por questões históricas ou artísticas, refletem o passado ou o presente; o que importa é que o bem possa ser representativo para a região e não apenas para um país. 
Uma das razões que leva a compreender a Tava como elemento de integração do MERCOSUL Cultural é a existência de um território tradicional guarani, chamado por eles de Y'vy Rupá. Esse território faz parte da cosmologia Mbyá Guarani, sendo aquele transitado e habitado por seus ancestrais que atingiram a imortalidade, conseguindo alcançar a "Terra sem Mal". Trazendo para a perspectiva geográfica, esse território se assemelha a dimensão cultural apontada por Haesbaert (2011), uma vez que sua delimitação vai além dos espaços físicos, abrangendo também os espaços subjetivos no ideário de seu povo.

Deste modo, cabe dizer que esse mesmo território não é completamente habitado pelos Mbyá Guarani, ele existe subjetivamente, através dos trajetos percorridos pelos Mbyá desde antes da ocupação europeia e que deixaram marcas durante seus percursos. Tal território é a representação de um dos princípios apresentados por eles durante a realização do INRC e em seguida, durante o processo de elaboração do Dossiê da Tava pelo IPHAN, que a registrou no Livro de Lugares, em 2014, como Tava: Lugar de Referência para o povo Guarani (Figura 4). Um desses princípios é o da "territorialidade livre", isto é, o reconhecimento da importância para os guarani de transitarem livremente pelo território tradicional.

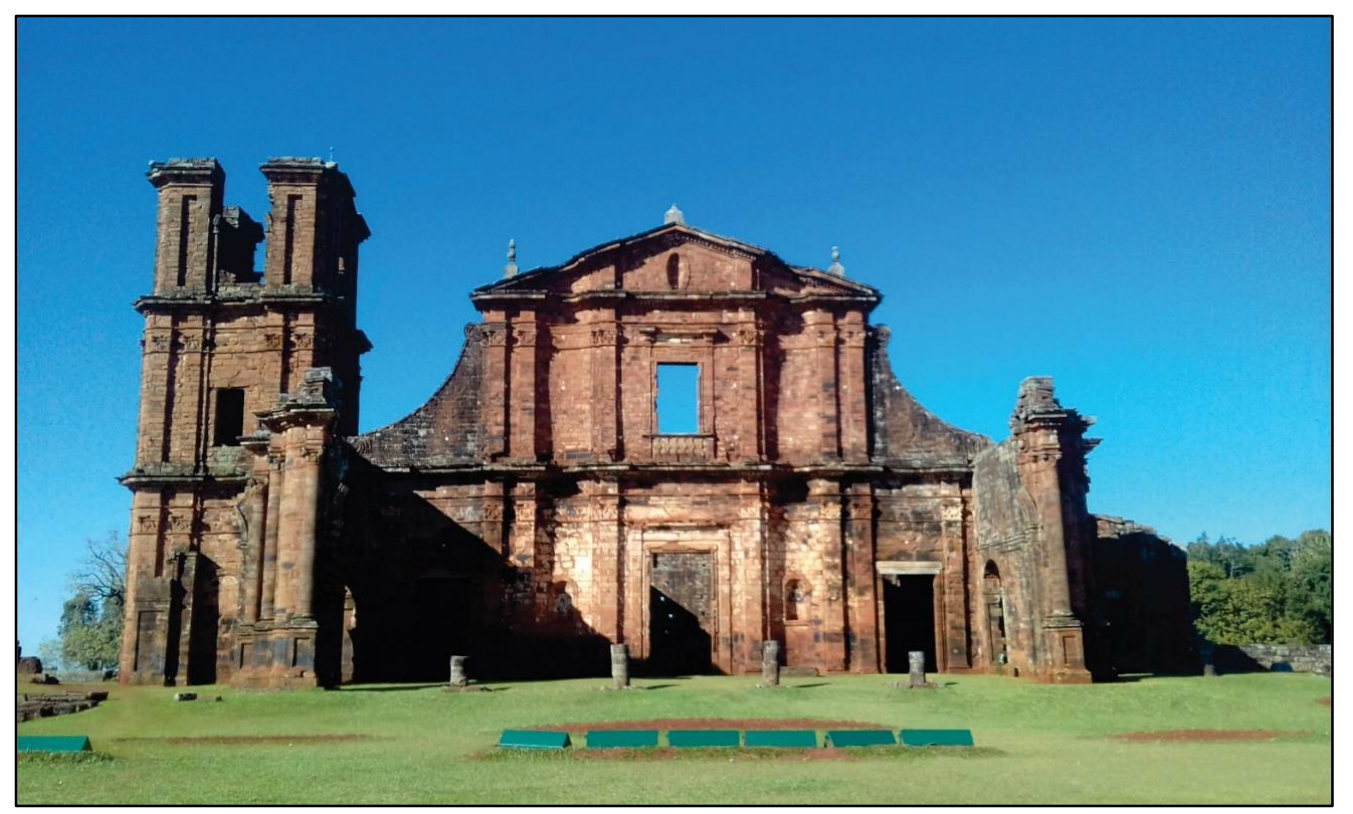

Figura 4 - Remanescente da Igreja de São Miguel Arcanjo e Tava para o povo Mbyá Guarani. São Miguel das Missões/RS.

Foto: Helena Faller. Agosto/2018.

Considerando o princípio da territorialidade livre, que consiste no caminhar livremente pelo território tradicional, visitando parentes, identificando novas tava, erguendo novas aldeias; e considerando que este território tradicional ocupa parte do Paraguai, da Argentina e do Brasil, o reconhecimento da Tava como Patrimônio Cultural do MERCOSUL a transforma no alicerce do debate acerca do percurso dos guarani por entre os três países. A Tava é a representação não só da 
integração política entre esses países, como também é o reflexo da integração cultural entre diferentes povos e culturas.

O reconhecimento da Tava de São Miguel Arcanjo não dá aos guarani o poder de atravessar as fronteiras políticas dos Estados sempre que quiserem, mas possibilita uma sensibilização aos países envolvidos de discutirem uma política pública específica para essa situação. Além disso, esse reconhecimento não é relevante apenas para o povo Guarani, visto que a tava em questão é um remanescente da Igreja de São Miguel Arcanjo, templo da redução jesuítica de mesmo nome; para os guarani, todo remanescente das igrejas das reduções que foram construídas por seus antepassados são tava, conforme foi falado por eles em visita na Tekoá Koenju ${ }^{9}$.

Assim, a existência dessas tava intensifica a participação desse grupo no desenvolvimento do projeto missional, sem contar que essas edificações são marcas do passado missioneiro, parte da formação histórica da Argentina, Brasil e Paraguai. Seja pela cosmologia guarani, seja pela história missioneira, não há como negar a importância desse bem para o MERCOSUL e sua capacidade de promover a integração que o bloco tanto busca.

\section{CONSIDERAÇÕES FINAIS}

$\mathrm{O}$ artigo propôs apresentar um breve panorama do processo de candidatura e reconhecimento da Tava: Lugar de Referência para o povo Guarani como Patrimônio Cultural do MERCOSUL, entendendo que este faz parte da pesquisa que vem sendo desenvolvida no âmbito do Mestrado Profissional em Preservação do Patrimônio Cultural pelo IPHAN.

O MERCOSUL Cultural, entidade do bloco responsável pelas diversas discussões envolvidas com a cultura e manifestações culturais da região mercosulenha, criou a categoria de Patrimônio Cultural do MERCOSUL, mediante a Decisão ${ }^{\circ} 55$ de 2012, que tem como principal proposta reconhecer o patrimônio que impulsione a integração cultural entre os países. Observando os critérios estabelecidos pela mesma Decisão, para se incluir um bem na Lista do Patrimônio Cultural do MERCOSUL, nota-se que a integração é fator preponderante. Para elevar um determinado bem a essa categoria é necessário que se identifique, a priori, sua importância para além do território nacional em que está localizado, isto é, identificar a relação do patrimônio com um ou mais países do MERCOSUL.

A Tava, enquanto Patrimônio Cultural do MERCOSUL, expressa a integração cultural proposta pelo MERCOSUL através de sua política integracionista. Por outro lado, essa integração é inerente ao bem, uma vez que independe de seu reconhecimento como patrimônio para que ela

\footnotetext{
${ }^{9}$ Conversa realizada com o cacique Aniceto, o vice-cacique Pascoal e a professora Patrícia durante a visita de campo na Tekoá Koenju (Aldeia Alvorecer) no dia 29 de agosto de 2018.
} 
ocorra. A tava é um lugar sagrado para o povo Mbyá Guarani, e sua identificação pelos karaí se torna uma representação espacial da presença Mbyá, ajudando a compor o seu território tradicional.

O território tradicional guarani existe no espaço através da organização das aldeias; porém, ele também se faz presente na subjetividade guarani, uma representação de sua ancestralidade que ficou marcada pelo tempo através dos caminhos que os antigos Mbyá percorreram. Assim, é possível entender a razão pela qual esse território ultrapassa os limites políticos nacionais, fazendose presente no Brasil, Argentina e Paraguai. Ademais, ele é uma marca da resistência do povo Mbyá; ainda que suas terras tivessem sido ocupadas e apropriadas em decorrência da colonização luso-hispânica, acarretando em parte de sua perda, o território tradicional nunca deixou de existir. Mesmo que tenham que lutar para ter um pedaço de terra delimitado politicamente e juridicamente, os Mbyá não deixam de caminhar por ele. É uma resistência cultural.

O reconhecimento da Tava como Patrimônio Cultural do MERCOSUL não se trata (apenas) de uma forma de compensação histórica ao grupo, na verdade, essa ideia nem foi cogitada no processo de candidatura. A intenção de inserir o bem na Lista do Patrimônio Cultural é para evidenciar a presença e a importância desse povo na construção histórica das nacionalidades sulamericanas. Além disso, tal reconhecimento pode gerar um debate político acerca das fronteiras e transição do povo guarani por entre elas. Existe, portanto, dois formatos territoriais que se sobrepõem: 1) território político protegido pelo poder do Estado e devidamente delimitado e organizado; 2) território tradicional existente a partir das manifestações culturais guarani ao longo dos anos e que possui uma delimitação subjetiva, marcada pela fluidez dos caminhos percorridos.

A sobreposição dos territórios e a relação de poder neles existentes apontam para uma fragilidade: a dificuldade do grupo de passar pelas fronteiras. O caminhar dos Mbyá Guarani é a essência do seu modo de vida, além de ser a causa das identificações das tava. Portanto, o reconhecimento desta Tava em especial atrai um leque de discussões sobre o direito de transitoriedade dos guarani pelo seu território. A Tava de São Miguel Arcanjo, por já estar localizada em uma zona de fronteira (município de São Miguel das Missões/RS), pode facilitar o diálogo entre os Estados nacionais na construção de políticas exclusivas para a territorialidade guarani. Seu reconhecimento não dá ao grupo o direito de caminhar livremente, mas, com certeza, é um elemento impulsor para tal resultado.

\section{REFERÊNCIAS}

BAPTISTA, J. O Temporal. São Miguel das Missões: Museu das Missões, 2009. (Dossiês Históricos do Museu das Missões; 1).

BRASIL. Presidência da República. Casa Civil. Subchefia para Assuntos Jurídicos. Decreto no 350, de 21 de novembro de 1991. Promulga o Tratado para a Constituição de um Mercado Comum 
entre a República da Argentina, a República Federativa do Brasil, a República do Paraguai e a República Oriental do Uruguai (TRATADO MERCOSUL). Portal da Legislação, Brasília, nov. 1991. Disponível em: http://www.planalto.gov.br/ccivil_03/decreto/1990-1994/d0350.htm. Acesso em: 18 out. 2018.

CUSTÓDIO, L. A. B. Ordenamentos urbanos nas Missões Jesuíticas dos Guarani: parte 1. Arquitextos, 200.05, ano 17, jan. 2017.

HAESBAERT, R. O mito da desterritorialização: do fim dos territórios à multiterritorialidade. Rio de Janeiro: Bertrand Brasil, 6 ed. 2011. 396p.

IPHAN. Tava: Lugar de Referência para os Guarani. Dossiê de Registro - Instituto do Patrimônio Histórico e Artístico Nacional. 2014.

LESSA, M. L. Mercosul Cultural: desafios e perspectivas de uma política cultural. Mural Internacional, Rio de Janeiro, v. 1, n. 2, p. 50-58, 2010.

MAEDER, E. J. A. Atlas territorial y urbano de las misiones jesuíticas de guaranies: Argentina, Paraguay y Brasil = Atlas territorial e urbano das missões jesuíticas dos guaranis: Argentina, Paraguai e Brasil. In.: E. J. A. M.; R. G. (Coord.). Instituto Andaluz del Patrimonio Histórico; colabora, Instituto do Patrimônio Histórico e Artístico Nacional do Brasil (IPHAN)]. - Sevilha: Consejería de Cultura, 2009.

MERCOSUL. Conselho do Mercado Comum. Secretaria do Mercosul. Decisão no 02, de 05 de agosto de 1995. Reunião de Ministros da Cultura. Assunção, ago. 1995. Disponível em: http://www.mercosur.int/innovaportal/v/2624/3/innova.front/decis\%C3\%B5es-1995. Acesso em: 18 out. 2018.

Decisão no 15, de 29 de junho de 2012. Estrutura Orgânica e Regulamento Interno do MERCOSUL Cultural. Mendonza, jun. 2012. Disponível em: http://www.mercosur.int/innovaportal/v/4393/2/innova.front/2012.Acesso em: 18 out. de 2018.

MERCOSUL. $\quad$ Brasília, $2012 . \quad$ dez. 2018 Disponível
http://www.mercosur.int/innovaportal/v/4393/2/innova.front/2012. Acesso em: 19 out. de 2018.

STELlo, V. F. Além das Reduções: A Paisagem Cultural da Região Missioneira. 2013. 238 f. Tese (Doutorado em Planejamento Urbano e Regional) - Universidade Federal do Rio Grande do Sul, Porto Alegre, 2013.

OLIVEIRA, R. C. A geopolítica do Mercosul. Revista Dia-Logos, Rio de Janeiro, v. 1, p. 41-46, 1997. 